\title{
Letter-by-letter processing in the phonological conversion of multiletter graphemes: Searching for sounds in printed pseudowords
}

\author{
RONALD PEEREMAN, MURIELE BRAND, and ARNAUD REY \\ University of Bourgogne and L.E.A.D.-C.N.R.S., Dijon, France
}

\begin{abstract}
Current models of word reading differ in their descriptions of how print-to-sound conversion is performed. Whereas a parallel procedure is generally assumed, the dual-route cascaded model developed by Coltheart and colleagues (Coltheart, Rastle, Perry, Langdon, \& Ziegler, 2001) holds that the nonlexical conversion operates letter by letter, serially from left to right. An interesting aspect of the hypothesized serial procedure is that only the first letter of two-letter graphemes is thought to cause activation of its corresponding phonological code, the second letter of multiletter graphemes being directly merged with the preceding letter to form a complex grapheme. This hypothesis was examined in a task in which participants had to detect target phonemes in visually presented pseudowords. The data suggest that phonological codes associated with all the letters of the multiletter graphemes are activated.
\end{abstract}

Reading words aloud requires readers to match orthographic units with phonological ones. A question that has attracted considerable debate is how this mapping proceeds (Frost, 1998). The dual-route theory posits that access to the phonological code of a printed word can either follow lexical access or be based on an analytical procedure that converts sublexical orthographic units into phonological units (see, e.g., Coltheart, Curtis, Atkins, \& Haller, 1993; Forster \& Chambers, 1973; Taft, 1991). Within this theoretical framework, one important issue concerns the way the analytical conversion is performed. According to various models (e.g., Norris, 1994; Taft, 1991), all orthographic units of the word (e.g., graphemes) are mapped in parallel to the corresponding phonological codes (e.g., phonemes). Such a view is also espoused by parallel distributed processing (PDP) models of phonological conversion (Plaut, McClelland, Seidenberg, \& Patterson, 1996; Zorzi, Houghton, \& Butterworth, 1998). Conversely, the dual-route cascaded (DRC) model (Coltheart et al., 1993; Coltheart, Rastle, Perry, Langdon, \& Ziegler, 2001), an instantiation of the dual-route theory, holds that the phonological conversion of sublexical units operates serially. Hence, although the lexical and the analytical procedures operate in parallel in the DRC model, the phonological code is built up sequentially, from left to right, by the analytical procedure. Finally, the phonological codes accessed by the two procedures are merged in a common final phoneme recipient. The present study

M.B. is now at the University of Provence. Correspondence concerning this article should be addressed to R. Peereman, L.E.A.D.-C.N.R.S., Université de Bourgogne, Pôle AAFE, BP26513, 21065 Dijon Cedex, France (e-mail: peereman@u-bourgogne.fr). was undertaken to examine a particular aspect of the serial hypothesis.

The assumption that letter strings are processed serially during phonological conversion has been supported by the finding that low-frequency words including an irregular/ inconsistent print-to-sound association are penalized in naming - especially when the irregularity occurs early in the letter string (Coltheart \& Rastle, 1994; Content, 1991; Content \& Peereman, 1992; Jared \& Seidenberg, 1990; Rastle \& Coltheart, 1999). The DRC model can account for this serial position effect, since it assumes that letter strings are converted serially, from left to right. Indeed, because the whole phonological representation can be quickly accessed through lexical retrieval, the sequential procedure has time only to deliver phonological codes to the phoneme system for the initial portion of a word before lexical retrieval occurs. In contrast, for words including late irregularities, the whole phonological representation is thought to be addressed before the phonological conversion of the ending graphemes. Thus, only words having early irregularities suffer from the activation of conflicting phonological codes in the phoneme system.

An interesting aspect of the serial hypothesis of the DRC model is that the phonological translation is supposed to make use of a letter-by-letter procedure, instead of a grapheme-by-grapheme procedure (Coltheart et al., 2001). The basic finding leading to this hypothesis is that pseudowords are pronounced less rapidly when they contain complex graphemes, such as EA in FEAPH (the whammy effect; Rastle \& Coltheart, 1998; see also Joubert \& Lecours, 2000; Rey, Jacobs, Schmidt-Weigand, \& Ziegler, 1998; Rey \& Schiller, 2005). A key characteristic of the hypothesized procedure is that letters are entered successively in the grapheme-to-phoneme conversion system and that the selected letters are matched to a set of 
grapheme-to-phoneme rules, with complex graphemes having a higher processing priority than do single-letter graphemes. For example, the conversion of the pseudoword FEAPH starts with the conversion of the grapheme $\mathrm{F}$, which activates the grapheme-to-phoneme rule $\mathrm{F} \rightarrow$ $/ \mathrm{f} /$. The second letter $\mathrm{E}$ is then entered and activates the grapheme-to-phoneme rule $\mathrm{E} \rightarrow / 3 \mathrm{z} /$. When the third letter $\mathrm{A}$ is entered for conversion, it is combined with the second letter E to activate the grapheme-to-phoneme rule EA $\rightarrow$ /eI/. Simultaneously, the initial activation of the rule $\mathrm{E}$ $\rightarrow / 3:$ is inhibited. This assumption allowed the authors to predict that pseudowords that contain complex graphemes will be disadvantaged, because the phonemic code associated with the complex grapheme (in our example, /eI/) will conflict with the phonemic code associated with the first letter of the complex grapheme. Thus, a critical characteristic of the procedure is that whereas the first letter of a complex grapheme will cause activation of its corresponding phonological code, the second letter of the grapheme (A) will never be considered individually for phonological conversion, since it will be combined with the preceding letter to form the complex graphemic unit (EA). ${ }^{1}$ It is on this specific claim that the present study focuses.

The question of whether each letter of multiletter graphemes causes the activation of its phonological counterpart appears to be central in modeling word-reading processes. Several reasons especially motivate our interest in what might, at first, resemble an implementation detail. The first one lies in the ambiguity of current evidence for serial processing in phonological assembly. More specifically, although the whammy effect has been considered as evidence in favor of serial processing, it also appears compatible with a parallel processing hypothesis, provided that all the letters of complex graphemes pop up their phonological counterparts. In that alternative framework, a decrease in performance is expected, because the phonological code associated with each single letter should interfere with the phonological code of the complex grapheme. In other words, the whammy effect would constitute strong evidence for seriality only if the assumption that all letters of complex graphemes are phonologically converted is wrong. To our knowledge, this aspect of the serial procedure has not yet been empirically examined.

A second and related reason motivating the present study relates to pragmatic and arbitrary constraints in computer modeling. Although an obvious merit of computational models is to force detailed specifications (see, e.g., Jacobs \& Grainger, 1994), designers are pragmatically constrained to adopt some arbitrary decisions about particular mechanisms implicitly considered to be irrelevant details. However, computational details in the modeler's conceptualization can turn out to be critical factors in the success of the simulation, and previously unidentified theoretical issues can emerge as a result of the implementation enterprise (see Content \& Frauenfelder, 1996, for a discussion). The progressive letter concatenation hypothesis embodied in the DRC model constitutes such an unexplored feature. Moreover, it contrasts with alternative parallel models of phonological conversion that assume that all letters of multiletter graphemes produce phonological activation (e.g., Plaut et al., 1996). In short, the assumption that not all letters of multiletter graphemes cause phonological activation is a differencing characteristic of the current version of the DRC model and of parallel models of print-to-sound conversion. Modifying the DRC simulator so as to allow phonological activation to be caused by all letters might prove to be computationally easy, but drastic effects on performance have sometimes occurred following simple changes in computational models (see, e.g., Frauenfelder, 1996; Grainger \& Jacobs, 1996; Plaut et al., 1996). Finally, an additional reason motivating the present study is that multiletter graphemes are extremely common in such orthographies as English or French, and a full understanding of word reading requires us to examine how these units are processed.

In the present study, the hypothesis that phonological activation is associated with each of the letters in a complex grapheme was assessed using a phoneme detection task with printed pseudoword stimuli. Tasks requiring participants to identify letters in words or pseudowords have often been used to explore orthographic processing in lexical access (e.g., Gross, Treiman, \& Inman, 2000) and the flow of activation between the orthographic and the phonological systems (Hooper \& Paap, 1997; Ziegler \& Jacobs, 1995). Similarly, several studies have explored auditory word recognition through the use of phoneme detection tasks (e.g., Frauenfelder \& Segui, 1989). Interestingly, the data in several studies also suggest the existence of early interactions between phonological and orthographic codes activated by means of bimodal presentations (e.g., Borowsky, Owen, \& Fonos, 1999; Dijkstra, Frauenfelder, \& Schreuder, 1993). In the experiment reported below, we used a new paradigm in which participants decided whether or not a target vowel phoneme was present in the phonological code of visually presented pseudowords. According to the same logic as that underlying the letter search task, searching for sounds in the phonological code of printed material should shed some light on phonological (instead of orthographic) activation during reading. Although phoneme detection is not yet handled by the DRC implementation (Coltheart et al., 2001), it can be conceived as resulting from an activation readout of the final phoneme recipient to which both lexical and nonlexical information converge. Pseudoword stimuli were therefore used, instead of words, to ensure that the phonological code of the letter string had to be built analytically and could not be addressed lexically. Consequently, because the phonological code of pseudowords can be obtained only through the nonlexical procedure, any activation of spurious phonemes during conversion should affect performance in the detection task.

French pseudowords were visually presented and were followed $150 \mathrm{msec}$ later by the auditory presentation of a target vowel phoneme. In the critical trials, pseudowords (e.g., AUCLET, pronounced /okle/) included a complex grapheme (i.e., AU pronounced /o/), and a negative re- 
sponse was expected (i.e., the target phoneme was absent from the pronunciation of the pseudoword). In these trials, the target phoneme corresponded to the pronunciation of either the first (i.e., /a/) or the second (i.e., /y/) letter of the complex grapheme (AU). Note that in order to produce a correct response, the participants have to process the pseudoword phonologically and cannot simply determine whether the target phoneme matches any letters in the pseudoword. Indeed, a strategy based on a letter search, instead of a phoneme search, would necessarily cause erroneous responses, since the target phoneme always matches the first or the second letter of the complex graphemes. A third (control) condition was added in which the target phoneme was absent from the pronunciation of the pseudoword (e.g., to detect /i/ in AUCLET). The DRC model predicts that only the first letter of the complex grapheme will cause activation of its phonological code. Accordingly, it should be more difficult to decide that the phoneme is absent from the pronunciation of the pseudoword when it corresponds to the pronunciation of the first letter of the complex grapheme than when it corresponds to the second letter of the complex grapheme. Because performance was examined on trials calling for negative responses, a simple interpretation of the effects in terms of a serial search for the target phoneme was unlikely. Indeed, the entire phonemic chain had to be considered, given that the target phoneme could appear in any serial position in the pseudoword.

\section{METHOD}

\section{Participants}

Thirty undergraduate students at the University of Bourgogne participated in the phoneme detection task. Thirty additional students were involved in a control phoneme-matching task. All were native French speakers and had normal or corrected-to-normal vision.

\section{Stimuli and Procedure}

Forty-eight mono- or disyllabic pseudowords (five to seven letters long) including a complex vocalic grapheme served as the experimental stimuli. The complex grapheme could be ou (pronounced /u/; e.g., ROUDE), AU (/o/; e.g., VAULE), AI (/ع/; e.g., JAIBE), or EI (/ع/; VEIFA). A key characteristic of the complex graphemes was that, in all cases, the two letters constituting the grapheme are pronounced differently when occurring as single vowels. For example, in French, the letters $\mathrm{O}$ and $\mathrm{U}$ included in the grapheme ou are pronounced /o/ and $/ y /$ when occurring separately, as in the words ROSE and RUSE. For each experimental item, four different target phonemes were used. The target phoneme could correspond to the pronunciation of the first or the second letter of the complex grapheme (the Letter 1 and Letter 2 conditions; e.g., /o/ and /y/ for ROUDE), to the pronunciation of a vowel not occurring in the pseudoword (the Letter Absent condition; e.g., /i/ in ROUDE), or to the correct pronunciation of the complex grapheme (the Grapheme condition; /u/ in ROUDE). The pseudowords are listed in the Appendix. For the purposes of the detection task, and in order to balance the number of times each target phoneme was present in or absent from the pronunciation of the pseudoword, 72 filler pseudowords were added. Half of them had single vocalic graphemes, and the other half had complex vocalic graphemes. To avoid strategic bias, the serial position of the critical vocalic grapheme was varied in both the experimental and the filler pseudowords. There were equal numbers of trials in which the target phoneme was present or absent.
Given that four different complex vocalic graphemes were used and that the pronunciation of each of their letter constituents served as targets, there were a total of seven different target phonemes $(/ \mathrm{u} /$, $/ \mathrm{o} /$, and $/ \mathrm{e} /$ for the complex graphemes and $/ \mathrm{a} /, / \mathrm{i} /, / \mathrm{y} /$, and $/ \mathrm{e} /$, as well as $/ \mathrm{o} /$, for the individual letters). The target phonemes were recorded by a female native speaker of French and were digitized at a sampling rate of $44 \mathrm{kHz}$, using 16-bit analog-to-digital conversion.

Since four different target phonemes were used for each experimental pseudoword, four different lists of trials were created, so that no participant was presented with the same pseudoword more than once. The lists were counterbalanced so that each experimental pseudoword was paired with the four different target phonemes. Each list consisted of the 48 experimental pseudowords and the 72 fillers. Ten additional trials were used for practice. The pseudowords were presented in lowercase on a computer screen. For each trial, a warning signal was presented for $500 \mathrm{msec}$, immediately followed by the pseudoword. The target phoneme was then presented through headphones $150 \mathrm{msec}$ after the onset of the pseudoword display. According to findings obtained using the masked priming paradigm (Ferrand \& Grainger, 1993), the use of such a positive delay should allow the automatic activation of phonological codes associated with the pseudoword before the presentation of the target phoneme. The pseudoword stimulus remained on the screen until the participant responded. The participant was asked to decide as quickly and accurately as possible whether the target phoneme was present in or absent from the pronunciation of the letter string. Responses were given by pressing one of two buttons of a response box. Response latencies were measured from the onset of the pseudoword display until the participant responded.

Because different phonemes were used in the Letter 1, Letter 2, and letter-absent conditions, a control phoneme-matching task was included to ensure that differences in performance across conditions did not simply follow from variations in the phonological similarity between the correct pronunciation of the complex grapheme and the target phonemes used in the Letter 1, Letter 2, and letter-absent conditions. The stimulus lists were similar to those in the phoneme detection task, except that the pseudoword display was replaced by the auditory presentation of the phoneme corresponding to the complex grapheme. The time interval between the two phonemes was $250 \mathrm{msec}$. Response latencies were measured from the outset of the second phoneme. The participants were asked to indicate whether the two successive phonemes were identical or not by pressing one of two response buttons.

\section{RESULTS}

Phoneme detection latencies smaller than $250 \mathrm{msec}$ or longer than $1,500 \mathrm{msec}$ were discarded, as well as latencies exceeding 2.5 standard deviations above the participant mean (1.6\% of the observations). Mean latencies for yes (target phoneme present) and no (target absent) responses were 780 and $831 \mathrm{msec}$, respectively. The corresponding percentages of errors were $6.8 \%$ and $10 \%$. The mean response latencies and error rates on the experimental pseudowords for the three target-absent phoneme conditions (Letter 1, Letter 2, and letter absent) are presented in Table 1. Mean latency and mean error were $774 \mathrm{msec}$ and $6.9 \%$, respectively, in the grapheme condition.

Phoneme detection performance was analyzed (in ANOVAs, by participants, $F_{1}$, and by items, $F_{2}$ ) as a function of the three absent target phoneme conditions. There was a reliable effect of condition on latencies $\left[F_{1}(2,58)=\right.$ $\left.18.5, p<.001 ; F_{2}(2,94)=12.9, p<.001\right]$. Latencies were slightly longer in the Letter 2 than in the Letter 1 condi- 
Table 1

Mean Detection Latencies (in Milliseconds), Percentages of Detection Errors, and Corrected Latencies in the Letter 1, Letter 2, and Letter-Absent Conditions (With Standard Deviations)

\begin{tabular}{|c|c|c|c|c|c|c|}
\hline & \multicolumn{2}{|c|}{$\begin{array}{l}\text { Letter } 1 \\
\text { (e.g., /o/ in } \\
\text { ROUDE) }\end{array}$} & \multicolumn{2}{|c|}{$\begin{array}{l}\text { Letter } 2 \\
\text { (e.g., /y/ in } \\
\text { ROUDE) }\end{array}$} & \multicolumn{2}{|c|}{$\begin{array}{l}\text { Letter Absent } \\
\text { (e.g., /i/ in } \\
\text { ROUDE) }\end{array}$} \\
\hline & $M$ & $S D$ & $M$ & $S D$ & $M$ & $S D$ \\
\hline Detection latencies & 841 & 83 & 865 & 68 & 787 & 89 \\
\hline Detection errors & 10.9 & 13.5 & 10.7 & 11.6 & 7.9 & 11.2 \\
\hline Corrected latencies* & 247 & 101 & 244 & 69 & 181 & 90 \\
\hline
\end{tabular}

Note-Mean performance in the by-item analyses. ${ }^{*}$ RT differences between the phoneme detection and the phoneme-matching tasks.

tion, but the difference did not reach significance in the by-item analysis $\left[F_{1}(1,29)=4.26, p=.048 ; F_{2}(1,47)=\right.$ $2.2, p=.14]$. Conversely, the Letter 1 and the Letter 2 conditions yielded longer latencies than did the letterabsent condition $\left[F_{1}(1,29)=27.3, p<.001 ; F_{2}(1,47)=\right.$ $22.2, p<.001]$. As is shown in Table 1 , errors were more frequent in the Letter 1 and Letter 2 conditions than in the letter-absent condition, but the effect of condition was not significant $\left[F_{1}(2,58)=2.2, p=.11 ; F_{2}<1\right]$.

Similar analyses were carried out on response times (RTs) in the control phoneme-matching task, to examine whether the three absent target phoneme conditions differed with regard to phonemic discriminability between the target phoneme and the pronunciation of the complex grapheme. Mean RTs were 594, 619, and $607 \mathrm{msec}$ for the Letter 1, Letter 2, and letter-absent conditions, respectively. The effect of condition was reliable by items and approached significance by participants $\left[F_{1}(2,58)=\right.$ $\left.2.71, p=.075 ; F_{2}(2,94)=8.91, p<.01\right]$. Latencies were not significantly longer in the Letter 1 and Letter 2 conditions than in the letter-absent condition (both $F_{\mathrm{S}}<1$ ), but RTs were longer in the Letter 2 condition than in the Letter 1 condition $\left[F_{1}(1,58)=5.42, p<.05 ; F_{2}(1,94)=\right.$ $17.81, p<.01]$. Hence, although the pattern of data did not match the results observed in the phoneme detection task, variations occurred across conditions with regard to phonemic discriminability between the target phoneme and the pronunciation of the complex grapheme. Therefore, an additional by-item analysis was performed on corrected latencies computed as the differences between RTs in the phoneme detection and the phoneme-matching tasks. This made it possible to correct detection latencies for the potential influence of the difficulty to discriminate between the target phoneme and the correct pronunciation of the complex grapheme in the detection task. RTs differences between the phoneme detection and the phonemematching tasks are presented in Table 1 . There was a main effect of target phoneme $[F(2,94)=9.7, p<.001]$. The Letter 1 and Letter 2 conditions produced longer latencies than did the letter-absent condition $[F(1,47)=19.4$, $p<.001]$, but the slight difference between the Letter 1 and Letter 2 conditions observed in the previous analyses vanished $(F<1)$.

\section{DISCUSSION}

The purpose of the present study was to examine whether single letters are phonologically converted when they form multiletter graphemes. According to the serial procedure embodied in the DRC model (Coltheart et al., 2001), phonological coding operates letter by letter. In the case of a two-letter grapheme, the phonological code of the first letter is initially activated. When the second letter enters the conversion process, it merges with the preceding letter to constitute a complex grapheme from which the correct phonological code is retrieved. Hence, letters that do not occur at the beginning of complex graphemes never activate their corresponding phonological codes. To assess this hypothesis, a task was used that required the participants to detect simple vowel phonemes in the phonological code of visually presented pseudowords. Following the serial procedure implemented in the DRC model, we predicted that it should be more difficult to decide that the target phoneme does not occur in the phonological code of the pseudowords when it corresponds to the pronunciation of the first letter of the complex grapheme than when it corresponds to the pronunciation of the second letter of the vowel digraph. The prediction was not supported by the data. It was not harder to decide that the target phoneme was not present in the pseudoword when it matched the phonological code of the first letter than when it matched the phonological code of the second letter of the complex grapheme. However, these two conditions yielded longer latencies than when the target phoneme was not present in the pseudoword phonology and did not correspond to the sound of single letters.

One might think that the use of pseudowords could have caused the participants to try to generate different pronunciations before responding, thereby causing phonological activation of the single letters included in the complex graphemes. However, the complex graphemes used in the study occur frequently in French words $(17 \%$ of the lexical entries of the Brulex database developed by Content, Mousty, \& Radeau, 1990), and pseudowords should not have been particularly difficult to convert phonologically. An additional set of 30 participants pronounced these pseudowords with an average onset latency of $626 \mathrm{msec}$ and a percentage of error of $2.7 \%$. These results seem similar to those generally found for the naming of multisyllabic pseudowords (e.g., Ferrand \& New, 2003).

Although the data do not support the tested DRC assumption about phonological conversion, they are consistent with the hypothesis that both of the phonemes corresponding to the first and second letters of the complex grapheme are activated prospectively during the online processing of the nonword. Since a similar interference is observed with phoneme detection latencies, it indicates that both phonemes receive similar activations. This prospective view can, however, be opposed to an alternative interpretation, according to which the results reflect a retrospective influence from the target phoneme to the nonword letter string. In this case, during a later stage of 
processing related to target phoneme verification, one can assume that letters automatically activate their sounds, which induces an inhibition on response latencies akin to the kind of interference observed in Stroop situations. It should be noted, however, that even if this late retrospective influence occurs, the DRC assumption still leads to the prediction that the first phoneme should produce more interference than the second one. This is because the distracting influence of integrating the target phoneme with a possible pronunciation of a letter in the nonword should be more detrimental for performance when the pronunciation of the letter is highly activated, as DRC assumes for the first letter of complex graphemes.

As was discussed above, the present data appear compatible with two different descriptions of the processes at work, but an analysis of the participant's response speed seems to provide an argument against the retrospective interpretation. Indeed, if the effect is due to a late retrospective influence from the target phoneme, slow participants should be more affected by these processes and should, therefore, produce a larger effect. On the other hand, fast participants not only should be less affected by this late interference, but might even not show the effect at all. We tested this prediction by sorting the participants according to their mean RTs on correct yes responses (a measure that is distinct from the investigated dependant variable-i.e., no responses) and by parsing the participants following the median of the RTs. Contrary to the prediction of the retrospective hypothesis, no interaction was observed between response speed and target phoneme $[F(2,56)=1.08, p=.35]$, indicating that there was no increase of the target phoneme effect for the slow participants. Similarly, the main effect of target phoneme was significant $[F(2,56)=18.6, p<.001]$, demonstrating that the fast participants were as affected as the slow participants by the type of target phoneme. The fact that the fast participants did display the effect even suggests that its locus was confined to task requirements and, very likely, to phonological conversion.

The task that we used in the present experiment provides, we believe, a new tool for studying phonological conversion processes. However, before drawing strong conclusions from a new experimental paradigm, several parametric manipulations are usually required, in order to precisely understand the interaction between the various processes involved in the task. In the present situation, parametric manipulations of the interstimulus interval (ISI), the position of the conflicting letter in the string, or the presentation duration of the nonword could definitely allow us to further constrain the test of the serial hypothesis. Indeed, observing no difference between the first and the second phonemes is not sufficient to conclude that there are no differences. For example, the stronger activation of the first phoneme, predicted by the DRC model, could emerge with a slightly different ISI. We think, however, that this is unlikely, because the presentation of the target phoneme was precisely chosen to fall within a temporal window corresponding to phonological conver- sion. Further parametric manipulations of the ISI could, however, confirm this possibility.

The present data suggest that individual letters are mapped to their corresponding phonological codes even when they are part of multiletter graphemes. In line with such a view, both Plaut et al.'s (1996) and Zorzi et al.'s (1998) models use orthographic encoding schemes in which letters occurring in complex graphemes are individualized, although units for multiletter graphemes are also allowed in Plaut et al. Thus, the data seem compatible with current PDP implementations of spelling-to-sound mapping, and they are consistent with recent evidence pointing to the activation of competing phonological codes during the phonological conversion of pseudowords (Lange, 2002).

Although the present study does not support the particular serial procedure implemented in the DRC model (Coltheart et al., 2001; Rastle \& Coltheart, 1998), we believe that it is not necessarily incompatible with a serial hypothesis. Indeed, the idea of a letter-by-letter procedure can still be valid once phonological activation corresponding to any single letter is assumed. In the case of multiletter graphemes, the phonological codes corresponding to single letters, as well as to letter groups, would be activated in the phoneme system. As has been supposed in multiple-levels models (e.g., Norris, 1994), a preference for larger units might then cause inhibition of the phonemic codes associated with single letters (Rey et al., 1998). Whether or not such a modification of the serial procedure would lead to quantitative differences in the performance of the model can be assessed only by means of simulations. As has been acknowledged by Coltheart et al. (2001), the question of how rules are serially applied has not yet been answered. However, in the case of serial models of phonological conversion, specifying how the serial procedure operates is far from being a mere implementation detail.

Simulations performed during the last decade have led researchers to specify the architectural differences between the models in greater detail. However, at the same time, it was observed that similar patterns of results were generally produced with very different architectures. In this respect, the contrast between serial and parallel processing was thought to be central, because clearly contrasting empirical predictions seemed to be attached to the different models. However, recent studies suggest that findings initially considered as supporting a serial procedure can also be accounted for within parallel models (e.g., Zorzi, 2000; but see Rastle \& Coltheart, 2000). For example, both Milostan and Cottrell (1998) and Zorzi (2000) showed that parallel conversion models produced the expected interaction between regularity and serial position. In the present study, we focused on an important and as yet unexplored characteristic of the serial procedure implemented in the DRC model that allowed us to make clear predictions with regard to the phonological activation associated with multiletter graphemes. Constraining the modeling of serial processes, the data sug- 
gest that all the letters present in multiletter graphemes are individually associated with their corresponding phonological code. We believe that our study represents a first attempt to specify possible serial procedures, thus making possible stronger empirical contrasts between serial and parallel models of phonological conversion.

\section{REFERENCES}

Borowsky, R., Owen, W. J., \& Fonos, N. (1999). Reading speech and hearing print: Constraining models of visual word recognition by exploring connections with speech perception. Canadian Journal of Experimental Psychology, 53, 294-305.

Coltheart, M., Curtis, B., Atkins, P., \& Haller, M. (1993). Models of reading aloud: Dual-route and parallel-distributed-processing approaches. Psychological Review, 100, 589-608.

Coltheart, M., \& Rastle, K. (1994). Serial processing in reading aloud: Evidence for dual-route models of reading. Journal of Experimental Psychology: Human Perception \& Performance, 20, $1197-$ 1211.

Coltheart, M., Rastle, K., Perry, C., Langdon, R., \& Ziegler, J. (2001). DRC: A dual route cascaded model of visual word recognition and reading aloud. Psychological Review, 108, 204-256.

Content, A. (1991). The effect of spelling-to-sound regularity on naming in French. Psychological Research, 53, 3-12.

Content, A., \& Frauenfelder, U. H. (1996). On the need for computer modeling: The case of language processing. Psychologica Belgica, 36, 113-144.

Content, A., Mousty, P., \& Radeau, M. (1990). Brulex: Une base de données informatisée pour le français écrit et parlé. L'Année Psychologique, 90, 551-566.

Content, A., \& Peereman, R. (1992). Single and multiple process models of print to speech conversion. In J. Alegria, D. Holender, J. Morais, \& M. Radeau (Eds.), Analytic approaches to human cognition (pp. 213-236). Amsterdam: Elsevier.

Dijkstra, T., Frauenfelder, U. H., \& Schreuder, R. (1993). Bidirectional grapheme-phoneme activation in a bimodal detection task. Journal of Experimental Psychology: Human Perception \& Performance, 19, 931-950.

Ferrand, L., \& GRAINGER, J. (1993). The time course of orthographic and phonological code activation in the early phases of visual word recognition. Bulletin of the Psychonomic Society, 31, 119-122.

FERrand, L., \& NEw, B. (2003). Syllabic length effects in visual word recognition and naming. Acta Psychologica, 11, 167-183.

Forster, K. I., \& CHAMBERS, S. M. (1973). Lexical access and naming time. Journal of Verbal Learning \& Verbal Behavior, 12, 627-635.

Frauenfelder, U. H. (1996). Computational modeling of spoken word recognition. In T. Dijkstra \& K. de Smedt (Eds.), Computational psycholinguistics: AI and connectionist models of human language processing (pp. 114-138). London: Taylor \& Francis.

Frauenfelder, U. H., \& Segui, J. (1989). Phoneme monitoring and lexical processing: Evidence for associative context effects. Memory \& Cognition, 17, 134-140.

Frost, R. (1998). Toward a strong phonological theory of visual word recognition: True issues and false trails. Psychological Bulletin, 123, 71-99.

Grainger, J., \& JACOBS, A. M. (1996). Orthographic processing in visual word recognition: A multiple read-out model. Psychological Review, 103, 518-565.
Gross, J., Treiman, R., \& Inman, J. (2000). The role of phonology in a letter detection task. Memory \& Cognition, 28, 349-357.

HoOPER, D. A., \& PAAP, K. R. (1997). The use of assembled phonology during performance of a letter recognition task and its dependence on the presence and proportion of word stimuli. Journal of Memory \& Language, 37, 167-189.

JACOBS, A. M., \& GRAINGER, J. (1994). Models of visual word recognition: Sampling the state of the art. Journal of Experimental Psychology: Human Perception \& Performance, 20, 1311-1334.

JARED, D., \& SEIDENBERG, M. S. (1990). Naming multisyllabic words. Journal of Experimental Psychology: Human Perception \& Performance, 16, 92-105.

Joubert, S. A., \& Lecours, A. R. (2000). The role of sublexical graphemic processing in reading. Brain \& Language, 72, 1-13.

LANGE, M. (2002). Activation of multiple phoneme associates of graphemes in visual word recognition. Brain \& Language, 81, 610-620.

Milostan, J. C., \& Cottrell, G. W. (1998). Serial order in reading aloud: Connectionist models and neighborhood structure. In M. I. Jordan, M. J. Kearns, \& S. A. Solla (Eds.), Advances in neural information processing systems 10 (pp. 59-65). Cambridge, MA: MIT Press.

NoRrIs, D. (1994). A quantitative multiple-levels model of reading aloud. Journal of Experimental Psychology: Human Perception \& Performance, 20, 1212-1232.

Plaut, D. C., McClelland, J. L., Seidenberg, M. S., \& Patterson, K. (1996). Understanding normal and impaired reading: Computational principles in quasi-regular domains. Psychological Review, 103, 56115.

Rastle, K., \& Coltheart, M. (1998). Whammies and double whammies: The effect of length on nonword reading. Psychonomic Bulletin \& Review, 5, 277-282.

Rastle, K., \& Coltheart, M. (1999). Serial and strategic effects in reading aloud. Journal of Experimental Psychology: Human Perception \& Performance, 25, 482-503.

Rastle, K., \& Coltheart, M. (2000). Serial processing in reading aloud: A reply to Zorzi. Journal of Experimental Psychology: Human Perception \& Performance, 26, 1232-1235.

Rey, A., Jacobs, A. M., Schmidt-Weigand, F., \& Ziegler, J. C. (1998). A phoneme effect in visual word recognition. Cognition, 68, B71-B80.

Rey, A., \& Schiller, N. O. (2005). Graphemic complexity and multiple print-to-sound associations in visual word recognition. Memory \& Cognition, 33, 76-85.

TAFT, M. (1991). Reading and the mental lexicon. Hillsdale, NJ: Erlbaum.

Ziegler, J. C., \& JACOBS, A. M. (1995). Phonological information provide early sources of constraint in the processing of letter strings. Journal of Memory \& Language, 34, 567-593.

ZoRZI, M. (2000). Serial processing in reading aloud: No challenge for a parallel model. Journal of Experimental Psychology: Human Perception \& Performance, 26, 847-856.

Zorzi, M., Houghton, G., \& Butterworth, B. (1998). Two routes or one in reading aloud? A connectionist dual-process model. Journal of Experimental Psychology: Human Perception \& Performance, 24, 1131-1161.

\section{NOTE}

1. According to Coltheart et al. (2001), "rules for larger graphemes are tested before rules using smaller graphemes" (p. 217). Thus rules for single letters occurring in multiletter graphemes are never tested because, as was stated by the authors, the letters that match a rule are removed from the letter string. 
APPENDIX

Pseudowords and Target Phonemes Used in the Letter 1, Letter 2, and Letter-Absent Conditions (With Pronunciations of the Complex Graphemes of the Pseudowords in Parentheses)

\begin{tabular}{|c|c|c|c|}
\hline \multicolumn{3}{|c|}{ Target Phoneme } & \multirow[b]{2}{*}{ Pseudoword } \\
\hline Letter 1 Condition & Letter 2 Condition & Letter-Absent Condition & \\
\hline$/ \mathrm{a} /$ & $/ \mathbf{i} /$ & $/ \mathrm{u} /$ & aiple (/ع/) \\
\hline /a/ & /i/ & $/ \mathrm{y} /$ & airpe $(/ \varepsilon /)$ \\
\hline$/ \mathrm{a} /$ & $/ \mathrm{y} /$ & /i/ & $\operatorname{aucret}(/ \mathrm{o} /)$ \\
\hline$/ \mathrm{a} /$ & $/ \mathrm{y} /$ & $/ \varepsilon /$ & aupile $(/ \mathrm{o} /)$ \\
\hline /a/ & /i/ & $/ \mathrm{o} /$ & baide $(/ \varepsilon /)$ \\
\hline /e/ & /i/ & $\mid y /$ & bleisso (/ع/) \\
\hline$/ \mathrm{a} /$ & /i/ & $/ \mathrm{y} /$ & bomaire $(/ \varepsilon /)$ \\
\hline /e/ & /i/ & /o/ & breifu $(/ \varepsilon /)$ \\
\hline /e/ & /i/ & /o/ & ceila $(/ \varepsilon /)$ \\
\hline$/ \mathrm{a} /$ & /i/ & $/ \mathrm{u} /$ & claige $(/ \varepsilon /)$ \\
\hline$/ \mathrm{a} /$ & /i/ & $/ y /$ & coltai (/ع/) \\
\hline$/ \mathrm{a} /$ & /i/ & $/ \mathrm{u} /$ & craide $(/ \varepsilon /)$ \\
\hline$/ \mathrm{a} /$ & $\mid y /$ & /i/ & daute $(/ \mathrm{o} /)$ \\
\hline /e/ & /i/ & $/ \mathrm{u} /$ & $\operatorname{docteit}(/ \varepsilon /)$ \\
\hline /e/ & /i/ & $/ \mathrm{o} /$ & dureit $(/ \varepsilon /)$ \\
\hline /e/ & /i/ & $/ \mathrm{y} /$ & eican $(/ \varepsilon /)$ \\
\hline /e/ & /i/ & $\mid \mathrm{y} /$ & eifral $(/ \varepsilon /)$ \\
\hline /e/ & /i/ & $/ \mathrm{o} /$ & fameir $(/ \varepsilon /)$ \\
\hline$/ \mathrm{o} /$ & $/ y /$ & $\mid \varepsilon /$ & foudi $(/ \mathrm{u} /)$ \\
\hline /a/ & $\mid \mathrm{y} /$ & $/ \mathrm{u} /$ & gaute $(/ \mathrm{o} /)$ \\
\hline$/ \mathrm{a} /$ & /i/ & /o/ & jaibe $(/ \varepsilon /)$ \\
\hline$/ \mathrm{a} /$ & /i/ & $/ \mathrm{y} /$ & laife $(/ \varepsilon /)$ \\
\hline$/ a /$ & /i/ & $/ \mathrm{o} /$ & luraime $(/ \varepsilon /)$ \\
\hline /e/ & /i/ & $/ \mathrm{u} /$ & mafeir $(/ \varepsilon /)$ \\
\hline /e/ & /i/ & $/ \mathrm{u} /$ & meica $(/ \varepsilon /)$ \\
\hline /e/ & /i/ & $/ \mathrm{u} /$ & meiva $(/ \varepsilon /)$ \\
\hline$/ \mathrm{a} /$ & /i/ & $/ \mathrm{o} /$ & muctai (/ع/) \\
\hline /o/ & $/ y /$ & $|\varepsilon|$ & oupale $(/ \mathrm{u} /)$ \\
\hline /o/ & $\mid \mathrm{y} /$ & /i/ & ourpet $(/ \mathrm{u} /)$ \\
\hline$/ \mathrm{o} /$ & $/ \mathrm{y} /$ & /i/ & pacrou $(/ \mathrm{u} /)$ \\
\hline$/ \mathrm{a} /$ & /i/ & $/ \mathrm{u} /$ & paime $(/ \varepsilon /)$ \\
\hline /o/ & $|y|$ & $\mid \varepsilon /$ & pamoupe $(/ \mathrm{u} /$ \\
\hline /o/ & $|y|$ & /a/ & pouve $(/ \mathrm{u} /)$ \\
\hline /o/ & $|y|$ & /i/ & proube $(/ \mathrm{u} /)$ \\
\hline /o/ & $/ y /$ & /i/ & ralou $(/ \mathrm{u} /)$ \\
\hline /a/ & $/ y /$ & $/ \mathrm{u} /$ & repauce $(/ \mathrm{o} /)$ \\
\hline$/ \mathrm{a} /$ & $\mid y /$ & $\mid \varepsilon /$ & rilaude $(/ \mathrm{o} /)$ \\
\hline$/ \mathrm{o} /$ & $\mid \mathrm{y} /$ & $\mid \varepsilon /$ & roude (/u/) \\
\hline$/ \mathrm{o} /$ & $/ \mathrm{y} /$ & /a/ & roume $(/ \mathrm{u} /)$ \\
\hline$/ \mathrm{a} /$ & $\mid \mathrm{y} /$ & /i/ & saure $(/ \mathrm{o} /)$ \\
\hline$/ \mathrm{a} /$ & $/ \mathrm{y} /$ & $\mid \varepsilon /$ & $\operatorname{sectau}(/ \mathrm{o} /)$ \\
\hline /o/ & $/ \mathrm{y} /$ & /a/ & troume $(/ \mathrm{u} /)$ \\
\hline /a/ & $/ \mathrm{y} /$ & $/ \mathrm{u} /$ & vaule $(/ \mathrm{o} /)$ \\
\hline /e/ & /i/ & $/ \mathrm{y} /$ & veifa $(/ \varepsilon /)$ \\
\hline /o/ & $/ \mathrm{y} /$ & /a/ & vicoute $(/ \mathrm{u} /)$ \\
\hline$/ \mathrm{a} /$ & $/ \mathrm{y} /$ & $/ \mathrm{u} /$ & $\operatorname{vimau}(/ \mathrm{o} /)$ \\
\hline$/ \mathrm{a} /$ & $/ \mathrm{y} /$ & /ع/ & $\operatorname{vraufe}(/ \mathrm{o} /)$ \\
\hline$/ \mathrm{a} /$ & $/ \mathrm{y} /$ & $/ \mathbf{i} /$ & vraute $(/ \mathrm{o} /)$ \\
\hline
\end{tabular}

(Manuscript received January 22, 2003;

revision accepted for publication February 2, 2005.) 